\title{
Pure Numbers Effects, Market Power, and Tacit Collusion in Posted Offer Markets
}

\author{
Douglas Davis \\ Virginia Commonwealth University \\ Richmond VA 23284-4000, USA \\ (804) 828-7140 \\ (804) 828-8884 (fax) \\ dddavis@vcu.edu
}

9 January 2009

\begin{abstract}
This paper studies the effects of seller concentration and static market power on tacit collusion in extensively repeated laboratory posted-offer markets. Contrary to the implications of some earlier research, we find that tacit collusion does not become pervasive with extensive repetition. In a 'strong no power' design persistently competitive outcomes are observed in markets with three or four sellers. Even duopolies are frequently competitive in this design. Unilateral market power raises prices, as predicted. However, static Nash predictions fail to organize outcomes across power treatments, because tacit collusion moves inversely with concentration. Excess capacity appears to explain observed tacit collusion levels.
\end{abstract}

Keywords: Experiments, Market Concentration, Market Power

JEL codes C9, D4 and L4

\footnotetext{
* Thanks for helpful comments to Asen Ivanov, Oleg Korenok, Robert Reilly, an associate editor and two referees. The usual disclaimer applies. Thanks also to Matthew Nuckols for programming assistance. Financial assistance from the National Science Foundation (SES 0518829) and the Virginia Commonwealth University Summer Research Grants Program is gratefully acknowledged. Instructions, an appendix and the experimental data are available at www.people.vcu.edu/ dddavis.
} 


\section{Introduction}

The impressive capacity of static Nash equilibrium (often competitive) predictions to organize market outcomes represents one of the most prominent successes of using laboratory methods to study market processes (see, e.g., Smith, 1982, or Plott, 1989). Markets organized under 'posted offer' trading rules, where sellers post prices to buyers on a take-it-or-leave-it basis, are no exception. Posted offer markets are of prominent interest in industrial organization because they parallel important aspects of retail exchange, and because they can be analyzed as games of Bertrand-Edgeworth competition. In such markets, competitive outcomes have been robustly observed even in thin markets with as few as three sellers (e.g., Ketcham et al. 1984). Further, the introduction of unilateral market power, in the form of capacity restrictions that assure sellers some sales at supra-competitive prices, has a price-increasing effect as static Nash equilibria predict (e.g., Davis and Holt, 1994, Davis et al., 2002)

Nevertheless, the organizing power of static Nash predictions in posted offer markets is imperfect. In some contexts, tacit collusion has been observed with frequency. A number of studies conclude that tacit collusion becomes problematic when the number of sellers is reduced to two (e.g., Fouraker and Siegel, 1963, Isaac and Reynolds, 2002). Of particular note is Dufwenburg and Gneezy (2000) who observe large supracompetitive deviations in duopolies of very short duration (10 trading periods), even when participants are re-matched into new markets each trading period. Potentially more generally problematic are results by Alger (1987) that suggest that extensive repetition may make tacit collusion pervasive in even less concentrated markets. Alger (1987) reports results of a series of two, three and four seller posted-offer markets that included as many as 140 periods each and finds that prices often increase after initially falling.

These behavioral results regarding the effects of intense concentration and repetition have some intuitive appeal. Extensive repetition allows sellers increased opportunities to develop a 'language of coordination' via their pricing activities. Further, to the extent that a two seller structure is not inherently anticompetitive, as results by Dufwenberg and Gneezy suggest, fewer sellers presumably make this task even easier.

Tacit collusion in the form of prices in excess of static Nash predictions have also been observed in some 'market power' experiments (e.g., Davis and Holt, 1994, Davis et 
al., 2008a, and Orzen, 2008). However, the same sort of intuitive results regarding the effects of increased concentration and repetition observed in no power designs do not clearly emerge from the literature examining power designs. In an experiment of relatively short duration, Davis and Holt reduce the number of sellers from five to three in a way that leaves static market power unchanged, and find that tacit collusion increases only slightly. In more extensively repeated contexts Orzen (2008) reports a tendency for tacit collusion in duopolies but not in thicker (quadropoly) markets, while Davis et al (2008a) find more evidence of tacit collusion in thicker (triopoly) markets than in duopolies. $^{1}$

In order to improve our understanding of when and how robustly Nash predictions may be expected to organize posted offer market outcomes, a good understanding of both the causes and pervasiveness of tacit collusion is important. This paper reports an experiment conducted to inform this question. Specifically, we use a 'near continuous' variant of the posted-offer trading institution to study the interrelationships between concentration, repetition and static market power in generating tacit collusion. ${ }^{2}$ By way of presummary, we find that, contrary to the implications of Alger (1987), tacit collusion is not a pervasive feature of posted-offer markets. In a 'strong' no power design, transactions prices in triopolies and quadropolies are uniformly quite competitive, and remain so even with very extensive repetition. Further, in the 'strong no power' design we find only sporadic evidence that increasing concentration to a duopoly generates

\footnotetext{
${ }^{1}$ Despite several common features Orzen (2008) and Davis et al. (2008a) differ in a number of important respects, including opposite predicted comparative static effects of concentration changes. Orzen examines a price setting game where a division of buyers into 'price sensitive' and 'convenience shopping' segments generates a predicted direct relation between the number of sellers and the price cost markup. Orzen finds that theoretical predictions organize behavior well in a 'static' condition where sellers are re-matched across periods (e.g., prices are higher in quadropolies than in duopolies). However, when participants remained in fixed groups duopoly prices increase, reversing the comparative static predictions observed in the re-matched group treatment. Davis et al. (2008a) studies a more standard design where a reduction in the number of sellers increases the central moments of the static NE mixing prediction. In markets with rematching Davis et al. (2008a) observe this predicted comparative static effect. However in fixed group markets, triopoly prices trended up toward those in the duopolies.

${ }^{2}$ In a related paper Davis et al. (2008b) hold the market structure fixed and examine the capacities of signaling activity and the underlying propensity of sellers behave cooperatively, to explain tacit collusion. Given a structure that is susceptible to tacit collusion (similar to the $3 w p$ treatment examined below), they find little evidence that signaling activity (at least the volume of signals sent) affects observed prices, but that 'type' importantly affects outcomes. As will be evident below, several of the structural alterations studied here appear to dominate the effects of 'type' on outcomes.
} 
higher prices as was observed, for example, in the re-mixed markets by Dufwenberg and Gneezy (2000).

We further find that unilateral market power sizably increases prices. However, static Nash predictions do not organize outcomes well across the power treatments because tacit collusion arises frequently, and moves inversely with concentration levels. In a follow-up experiment we explore the inverse relationship between tacit collusion and concentration, and find support for the conjecture that tacit collusion in posted offer markets is driven by a 'follow rate' which reflects the number (or, if only a subset is needed, the percentage) of 'other' sellers that must follow a signaler's price lead in order for the signaler to profit from supra-competitive prices in subsequent periods.

The remainder of this paper is organized as follows. Section 2 develops the experiment design and predictions. Section 3 presents the experimental procedures. Results appear in section 4. Section 5 considers some additional possible causes of tacit collusion in our markets, and reports a follow-up experiment. The paper concludes with a short discussion in Section 6.

\section{Experiment Design}

2.1 The Near-Continuous Posted-Offer Institution. The posted-offer trading institution has a long history in experimental economics (see, e, g., Ketcham et al. 1984). Trading occurs in a sequence of 'periods.' At the outset of each period, sellers, endowed with unit costs, simultaneously make price and maximum offer quantity decisions. Production is 'to demand' in the sense that sellers incur unit costs only for offered units that subsequently sell. Once all price-posting decisions are complete, a public display of prices appears, and a (simulated) buyer makes purchases, starting with the lowest priced units. In the case of a price tie, the buyer divides purchases as evenly as possible among the sellers posting the same price. The buyer routine continues making purchases until demand has been exhausted, no further units are available, or until unit values no longer exceed the lowest available price. The period concludes by showing each seller his or her own period sales and earnings.

In most respects, the posted offer implementation used here follows standard procedures. Our markets are distinctive, however, in that they are extensively repeated. Each 'treatment sequence' in our experiment consists of 220 trading periods. This large 
number of trading periods was made possible by truncating to seven seconds the maximum length of decision periods. ${ }^{3}$ Procedures are streamlined to facilitate the entry of pricing decisions. Bar graphs that supplement tabular displays of price choices and earnings similarly facilitate participants' interpretation of outcomes. ${ }^{4}$ In a previous related experiment Davis and Korenok (2008) establish that participants are quite capable of interpreting and responding to pricing results in trading periods of such short duration. Extensive repetition is particularly useful here in that it allows sellers considerable additional opportunities to coordinate their actions.

2.2 Supply and Demand Arrays. To examine interactions between concentration and unilateral market power in effecting tacit collusion, we use a 'strong no-power' design, where any seller can service the entire market, and a 'power' design, where sellers can unilaterally profit by raising their prices above the competitive level. In each case, we vary the number of sellers, $n=2,3$ and 4, creating a total of six treatment cells.

The strong no-power ('np') design shown in Figure 1 is a variant of a stark Bertrand environment examined by Dufwenberg and Gneezy (2000). As the figure illustrates, a buyer will purchase ten units at any price less than or equal to $\$ 6$ per unit. Symmetric sellers are endowed with ten units costing \$2 per unit, as the identifiers 'S1' to 'S4' printed below the supply schedule indicate. Thus, each seller can unilaterally service the entire market. Treatments are separated by the number of sellers. As the supply schedule labeled ' $\mathrm{S}_{2}$ ' indicates, aggregate supply in the two-seller ('2np') treatment consists of 20 units. Similarly, aggregate supply increases to 30 and then 40 units in the 3np and 4np treatments. Finally, as in Dufwenberg and Gneezy, we impose a price floor above unit costs to ensure strictly positive profits. Here sellers may not post prices below $\$ 3$.

Using standard arguments, one can readily establish that the competitive price of $\$ 3$ is the unique Nash equilibrium for the market stage game in the strong no power treatments. For example, suppose $n=2$. To see that $\$ 3$ is a Nash equilibrium, observe that at a price of $\$ 3$ each seller sells five units and earns $\$ 5$. Any deviation above $\$ 3$

\footnotetext{
${ }^{3}$ In a number of recent experimental studies, investigators have reduced the maximum length of decision periods in order to increase the decision-profile. Some pertinent oligopoly experiments include Deck and Wilson (2002, 2008), Davis and Korenok (2008), and Davis et al. (2008a,b).

${ }^{4}$ For a more complete description of the near continuous posted-offer trading institution, see Davis and Korenok (2008).
} 
reduces earnings to zero. For uniqueness, observe that no pair of different prices above \$3 can be part of an equilibrium strategy, since earnings for the seller posting the highest price will be zero. Similarly, no common price above \$3 can be an equilibrium, since either seller could increase earnings by reducing his or her price the minimum possible increment below the common price.

Figure 2 illustrates a complementary power (' $p$ ') design. As in the $n p$ design, demand remains fixed at ten units, which will be purchased at any price of $\$ 6$ or less. Supply conditions distinguish the two designs. In Figure 2 aggregate supply consists of a constant twelve units, offered at a $\$ 2$ per unit, which is divided evenly among the $n=2,3$ or 4 sellers. Unlike the strong no-power treatments, no minimum price constrains seller pricing decisions. $^{5}$

The restricted supply in Figure 2 creates market power. For example, in the twoseller (' $2 p$ ') treatment, sellers S1 and S2 may each offer six units for sale. Given that the buyer will purchase ten units in aggregate, the high pricing seller is assured of selling four units at a price of $\$ 6$ or less. Notice that $\$ 6$ cannot be an equilibrium price for this game, because at a common price of $\$ 6$ either seller can unilaterally increase sales to six units by reducing his or her price by the minimum possible increment. Incentives to undercut exist on any common price down to a lower bound $p_{2 \min }=\$ 4.67$, where selling six units as a low pricing seller just equal the security earnings from posting a price of $\$ 6 .{ }^{6}$ The equilibrium for this game involves mixing over a range of prices bounded by $\$ 6$ and $p_{2 \min }=\$ 4.67$. In a symmetric equilibrium, each seller prices according to a distribution, $F_{2}(p)$ that leaves the other seller indifferent between any price in the support of the distribution, and the security price, or $\left(1-F_{2}(p)\right) \times 6(p-2)+F_{2}(p) \times 4(p-2)=\$ 16$, or

$$
F_{2}(p)=\frac{3 p-14}{p-2} .
$$

\footnotetext{
${ }^{5}$ For purposes of consistency it might have been well to also impose a minimum price at $\$ 3.00$ in the $p$ treatments. In any case, sellers in the $p$ treatments posted prices below $\$ 3.00$ relatively infrequently. Of 11,880 price postings in the $p$ treatments only 535 (4.5\%) were below $\$ 3.00$. Further, nearly one third of these postings (148) occurred in the first 10 periods of the sequences, before many sellers posted initial prices. For periods 11 to 220 of the sequences (the periods analyzed below in the results section) only 387 of 11,340 decisions (3.4\%) were below $\$ 3.00$.

${ }^{6}$ That is, solve $\left(p_{2 m i n}-\$ 2\right) \times 6=(\$ 6-\$ 2) \times 4$.
} 
Solving numerically, the mean of $F_{2}(p), \bar{p}_{2}=\$ 5.25$ and the mean expected transactions price for the market, $\bar{p}_{2 p T}=\$ 5.17 .^{7}$

Reasoning similarly, in the $3 p$ treatment sellers mix over the range $[\$ 4, \$ 6]$ and price according to the distribution

$$
F_{3}(p)=\sqrt{\frac{2 p-8}{p-2}} .
$$

Again using numerical methods, the mean of $F_{3}(p), \bar{p}_{3}=\$ 4.50$ and the mean transactions price is $\bar{p}_{3 p T}=\$ 4.29$. For the $4 p$ treatment, the mixing range expands to $[\$ 3.33, \$ 6]$ and the symmetric equilibrium pricing distribution becomes

$$
F_{4}(p)=\sqrt[3]{\frac{3 p-10}{2 p-4}}
$$

The mean of $F_{4}(p), \bar{p}_{4}=\$ 3.73$ and the mean transactions price is $\bar{p}_{4 p T}=\$ 3.49 .^{8}$

The primary distinguishing features of the $p$ design for this investigation are that (a) static equilibrium prices in $p$ treatments exceed those in corresponding $n p$ treatments, and (b) that across $p$ treatments prices rise as the number of sellers fall.

2.4 Conjectures. Table 1 summarizes the experiment design. Moving down

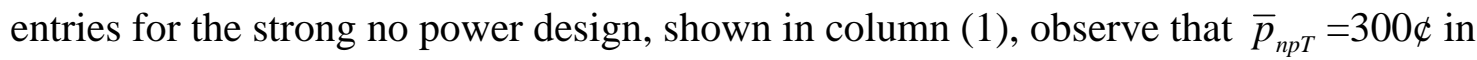
each case. As the experiments discussed above in the literature review suggest, we might anticipate more tacit collusion as concentration increases in this design, particularly when the number of sellers is reduced to two. Further, to the extent that results by Alger (1987) are pertinent, extensive repetition should generate increased levels of tacit collusion. This is a first conjecture.

Conjecture 1: In a strong no power design, tacit collusion increases with concentration. Further, tacit collusion becomes more pronounced with extensive repetition.

\footnotetext{
${ }^{7}$ We focus on mean transactions prices in the results section because they allow a more complete assessment of tacit collusion than mean posted prices (see note 13 below). Notice that $\bar{p}_{2 T}<\bar{p}_{2}$ because the expected price realizations are weighted by sales quantities, and the low pricing seller always enjoys a higher sales volume. An online appendix provides details of the mean transactions price calculations for the power treatments.

${ }^{8}$ Due to the constraints imposed by constant earnings and identical distributions, uniqueness in symmetric strategies follows obviously for each game $n=2,3$ and 4 . No demonstration of overall uniqueness for these mixed strategy equilibria exists. Cripps and Ireland (1988), however, does establish the uniqueness of the mixed strategy equilibrium for a two seller game in this 'box' design.
} 
Comparing across the strong no power and power designs, observe that the introduction of unilateral market power substantially increases (mean) static predicted prices. This second conjecture is to confirm results in related environments (e.g., Davis and Holt, 1994).

Conjecture 2: Holding the number of sellers fixed, shifting from the 'strong no power' treatment to a 'power' treatment raises prices.

Finally, within the power treatment notice that static Nash predictions move inversely with the number of sellers. Observe further, that to the extent tacit collusion is more easily organized in markets with fewer rather than more sellers, and to the extent repetition facilitates communication, these comparative static predictions should become more pronounced with repetition. This is our third conjecture.

Conjecture 3: In the power treatments tacit collusion increases with concentration. Extensive repetition enhances this effect.

\section{Experiment Procedures}

The primary experiment consists of six markets in each of the six design/number of seller treatment combinations, for a total of 36 markets. Data were collected in a series of six laboratory sessions. Each session consisted of two sequences. At the beginning of the first sequence, nine participants were divided into three markets, one with two sellers, a second with three sellers and a third with four sellers. Participants made a series of 220 repeated decisions in either an $n p$ treatment, or in a $p$ treatment after which the market was terminated without prior announcement. Following the conclusion of the first sequence, participants were reshuffled into a new set of three markets, and a second sequence began, this sequence using treatments in the design ( $p$ or $n p$ ) not used in the first sequence. The second sequence also consisted of 220 periods and was again terminated without prior announcement.

To control for potential order-of-sequence effects, sessions were blocked by designs, with the $p$ design treatments appearing first in three sessions and $n p$ design treatments appearing first in the remaining three sessions. Also, to minimize possible 'carryover' effects, participants were re-matched in a way that minimized re-contacts 
across sequences. ${ }^{9}$ This procedure generated a total of six $p$ and $n p$ markets in each number/design combination.

Finally, in all sessions sellers were given no information regarding underlying supply and demand conditions. Thus, sellers operated in light of only their private costs and the public messages of the market. ${ }^{10}$ Also, to avoid focal price effects, the $\$ 3$ price minimum was not announced in the instructions of the $n p$ sessions. Rather, participants encountered the price bound in the course of exchange. ${ }^{11}$

Subjects were 64 student volunteers enrolled in business and economics courses at Virginia Commonwealth University in the spring semester of 2005. All subjects were 'institution experienced' in the sense that they had participated a previous session in the near-continuous posted-offer trading institution, but in a different design. No one participated in more than one of the sessions reported here. Laboratory dollars were converted to U.S. dollars at a rate of each \$1 U.S. currency for each \$200 in the laboratory. Earnings for the roughly 100 minute sessions, ranged from $\$ 17.5$ to $\$ 32.50$ and averaged about $\$ 24.00$ (inclusive of a $\$ 6$ appearance fee). ${ }^{12}$

\footnotetext{
${ }^{9}$ Specifically, one triopolist and one quadropolist from the first sequence formed the second sequence duopoly. Similarly, a duopolist a triopolist and a quadropolist from the first sequence were combined to form the second sequence triopoly. The remaining first sequence participants (e.g., one duopolist, one triopolist and two quadropolists) formed the second-sequence quadropoly.

${ }^{10}$ Whether or not information regarding underlying aggregate supply and demand conditions should be provided to participants in market experiments is a controversial issue (see e.g., Smith 2003). However, results reported in Davis et al. (2008a) suggest that in environments like those studied here, with symmetric sellers and a simulated buyer, this choice does not importantly affect outcomes.

${ }^{11}$ In a pilot session, announcing a \$3 price minimum in the instructions led many sellers to open with a \$3 price, suggesting that the prior announcement of the minimum made it unnecessarily focal.

${ }^{12}$ In some instances more participants appeared for a session than could be used. These "alternates" were paid a \$10 appearance fee, and were invited to participate in a future session.
} 


\section{Results}

4.1 Overview. We present data in terms of mean transactions prices. ${ }^{13}$ The mean transaction prices paths for the strong no power and power treatments shown in Figure 3 provide an overview of experimental results. The no power treatments, shown in the left column of the Figure, illustrate a strong tendency for prices to collapse on the $\$ 3.00$ competitive prediction in the $3 n p$ and $4 n p$ treatments after 10 to 15 trading periods. Further, repetition does nothing to undermine the general competitiveness of markets in these treatments. Compared to the three and four seller treatments, transaction prices in the $2 n p$ treatment are less uniformly competitive. Nevertheless, throughout the sequence mean transaction prices in the $2 n p$ treatment are much closer to the competitive prediction than to the joint maximizing prediction.

Comparing mean transactions prices for the power treatments, shown in the right column of Figure 3, with the no power treatments in the left column reveals the large and persistent price-increasing effect of introducing unilateral market power. The right panels of Figure 3 make apparent two other features of results in the power treatments. Observe first that mean transactions prices in the power treatments do not follow the comparative static predictions associated with reducing the number of sellers. To the contrary, deviations from the static Nash prediction (shown in each panel as a dashed line) increase as the number of sellers increase. Notice second that although outcomes in the power treatments are generally more variable than in the no-power treatments, the bulk of price adjustments again occur in the first 10 to 15 trading periods.

One feature of results not evident from Figure 3 regards the variability of market outcomes within treatments. The mean transactions prices for the first and last half of each market (excluding initial adjustment periods 1-10) shown in Table 2 provide some

13 In a number of experimental investigations of tacit collusion (e.g, Davis et al., 2008b, Isaac et al., 1984, and Potters and Suetens, 2008), results are presented in terms of a 'collusive efficiency index' (or a related name), which summarizes the percentage of possible supra-competitive earnings extracted by sellers each period. Our interest in assessing both price (in conjecture 2) and tacit collusion (in conjectures 1 and 3) makes convenient the use of mean transactions prices here. In our no power treatments, the collusive efficiency index is essentially a linear transformation of the mean transactions price (e.g., the collusive efficiency of market $j$ in period $t, \psi_{j t}=\left(\pi_{j t}-\pi_{N E}\right) /\left(\pi_{J P M}-\pi_{N E}\right)=\left(\bar{p}_{T j t}-3\right) /(6-3)$, where $\pi_{j t}$ denotes realized profits, $\pi_{N E}$ denotes static Nash profits and $\pi_{J P M}$ denotes joint maximizing profits, and where $\bar{p}_{T j t}$ denotes the mean transactions price, 6 is the joint maximizing price and 3 is the competitive price). In the power treatments, this simple transformation breaks down, because the Nash prediction changes across treatments. Nevertheless, evaluation of outcomes in terms of $\psi_{\mathrm{jt}}$ does not affect our conclusions. 
pertinent insight. Inspecting the mean transactions prices for strong no power treatments, shown in the upper panel, the striking homogeneity of the 3np and 4np treatments is most noticeable, particularly when viewed in light of the high variability of outcomes in the power treatments, shown in the lower panel. Note also in the no power treatments, however, that in the $2 n p$ markets transactions prices were also very nearly competitive (e.g., within $15 \$$ of 300 ) in the majority of instances. Comparatively high mean prices for the $2 n p$ treatment are driven by substantially elevated prices in a pair of $2 n p$ markets for the first 105 periods, and by a different pair for the final 105 periods. In the remainder of this section we establish these observations more formally as findings by evaluating conjectures 1 to 3 , using as data the mean transactions prices in Table 2 .

4.2 Tacit Collusion in the Strong No Power Design. Table 3 presents data pertinent to the evaluation of tacit collusion in the strong no power design, the subject of conjecture 1. As indicated by the comparisons shown in columns (1) to (3) in the upper panel of the table, mean transaction price differences across treatments, while not terribly large (36 or less), are significantly higher in duopolies than in the first half of the triopolies or in both the first and second halves of the quadropolies. ${ }^{14}$

Nevertheless, the relatively higher prices in the $2 n p$ treatment provide only limited evidence that duopoly markets are importantly impacted by tacit collusion. Many 'competitive' experimental markets are often characterized by some non-trivial price variability, and there is no agreement among experimentalists as to the level of mean deviation from competitive predictions sufficient to classify a market outcome as 'tacitly collusive'. Suppose, however, that as in Davis et al. (2008b), we identify those markets in which sellers realize at least $10 \%$ of the maximum available supra-competitive profits (here within $30 \mathbb{\$}$ of the competitive prediction) as collusively impacted. As seen in the middle panel of Table 3, we are unable to reject the null hypothesis that mean prices in any of the strong no power treatments are in this sense collusively impacted.

Observe finally from the bottom of Table 3, that increased repetition does nothing to foster tacit collusion. To the contrary, as the negative entries at the bottom of the table

\footnotetext{
${ }^{14}$ In what follows we use the permutation, or Fisher's exact probability test for making comparisons across treatments, and the Wilcoxon test for comparing observed and predicted outcomes within treatments. We follow the convention of terming $p<.01$ as 'highly significant', $p<.05$ as 'significant' and $p<.10$ as 'weakly significant'
} 
indicate, mean transaction prices fall slightly in each of the three treatments. These results form a first finding.

Finding 1: In the strong no power design, tripolies and quadropolies are persistently competitive even with extensive repetition. Although duopoly prices exceed those in the trioplies and quadropolies, the duopoly treatment is not importantly impacted by tacit collusion, even after extensive repetition.

Finding 1 is interesting in light of previous results by Alger (1987) and Duwfenberg and Gneezy (2000). As Dufwenberg and Gneezy (2000) report, we find duopoly prices in the no power treatment significantly exceed those in the three and four seller counterparts. Nevertheless, our 'no power' duopolies are not consistently collusive, and mean transaction price deviations, are much smaller than Dufwenberg and Gneezy (2000) report. (In our duopolies mean transaction price deviations are about 11\% of the range between the competitive and joint maximizing outcome. In their comparable markets Dufwenberg and Gneezy observe a deviation of about 27\% of the same range.) Further, in contrast to the implications of Alger (1987), extensive repetition does not make posted offer markets inherently anticompetitive. To the contrary mean prices fall slightly (albeit insignificantly) in the second half of each strong no power treatment.

\subsection{Market Power versus the Strong No Power Design. Table 4 compares mean} transaction prices across the power and strong no power treatments. As seen in the upper panel of the table, the introduction of market power both significantly and sizably increases transactions prices relative to the strong no power treatment. Notice in the bottom panel of Table 4 that while in all power treatments mean prices increase slightly in the second half of sequences relative to the first, the differences are never significant. These results form a second finding, which largely calibrates our results with other pertinent studies (e.g., Davis and Holt, 1994).

Finding 2: Unilateral Market Power raises prices relative to the strong no power design. Repetition does not significantly increase prices in the power treatments.

4.4 Tacit Collusion in the Power Design. A predicted consequence of introducing market power is that mean prices move inversely with the number of sellers. However, as seen in the bottom two rows of Table 2, while mean prices in more concentrated markets tend to exceed those in their less concentrated counterparts, the differences are much smaller 
than predicted. Table 5 summarizes results of some statistical comparisons pertinent to these differences. As shown in the top panel of Table 5, while mean transaction prices tend to increase slightly with concentration in the power treatments, the differences are small, and significant in only one of the six comparisons (the comparison between $\bar{p}_{2 p T}$ and $\bar{p}_{4 p T}$ in the first sequence half, where a difference of 168 cents is predicted). The bottom panel of Table 5 highlights the reason for the smaller than predicted price differences across the power treatments: for the $2 p$ treatment, deviations from static Nash predictions are less than $30 \$$ ( $10 \%$ of the joint maximizing to minimum price range), but are both much larger on average and significant in the $3 p$ and $4 p$ treatments. These findings combine to form a third result.

Finding 3: Increased concentration does not significantly raise prices in the power design, because tacit collusion tends to be higher in three and four seller power treatments than in duopolies.

\section{5. "Follow Rates" and Tacit Collusion.}

Results of these extensively repeated markets parallel the existing literature in the sense that, relative to the strong no power treatment, a reduction of capacity sufficient to create market power tends to raise prices. However results are less consistent with the informal, albeit largely intuitive ideas that both concentration and repetition facilitate tacit collusion. In the strong no power treatment, we do observe some instances of larger price deviations in the $2 n p$ treatment than in the $3 n p$ or $4 n p$ treatment. However, these effects are not a consequence of increased repetition. Further, most $2 n p$ markets are quite competitive. More problematically, we observe clearer evidence tacit collusion in the power designs, but it decreases with concentration.

The purpose of this section is to explore this latter, rather curious result. Notice first that coordinated activity does not explain instances of tacit collusion. Identifying coordinated pricing or quantity posting activity, along with mechanisms for punishing 'defectors' who fail to comply with a tacit arrangement lies at the heart of antitrust policy towards tacit collusion. ${ }^{15}$ Table 6 provides some evidence regarding coordinated behavior in our markets. Columns (2) and (3) list the percentage of periods where sellers

\footnotetext{
${ }^{15}$ See, for example, section 2.1 of the U.S. Department of Justice and Federal Trade Commission Horizontal Merger Guidelines (1997).
} 
posted identical supra-competitive prices in the power and no power treatments. Sellers never posted the same price in more than 5.9\% of the time in any 105-period segment. Similarly, as seen in columns (4) and (5) sellers repeated a rotation of quantities across sellers (as would be consistent with a collusive quantity rotation scheme) no more than $3 \%$ of the time. Notably, both of these 'high' numbers occurred in duopoly treatments where sellers are quite likely to occasionally stumble on apparently coordinated price or quantity outcomes by chance. Further, those treatments with the most tacit collusion exhibited the least evidence of such coordinated behavior. For example, sellers in the $4 p$ markets posted the same prices in no more than $1.3 \%$ of periods, and never repeated a rotation of sales quantities across sellers. For this reason, we are skeptical that the development of a 'language of coordination' explains the tacit collusion observed in these markets.

Unstructured signaling and response activity represents a possible alternative explanation for observed tacit collusion. Both the costs of signaling and the likelihood that rivals respond to a signal may affect the success of such activity. Relative to the strong no power treatment, the costs of sending signals are lower in the power treatment, since sellers with power are, by definition, certain to sell at least some units each period as long as they price at or below the $\$ 6$ upper limit price. However, while reduced signaling costs might explain higher prices in the power treatments relative to the strong no power treatments, signaling cost differences cannot explain price patterns observed within the power treatments, because the amount of unilateral power (and thus the extent to which signaling costs are low) moves directly with concentration. In the $2 p$ design a seller making a price posting 'signal' of $\$ 6$ foregoes the profits associated with the sale of $1 / 3$ of capacity (two out of six available units). In the $3 p$ and $4 p$ treatments a similar $\$ 6$ signal implies that sellers forego earnings from the sale of $1 / 2$ and $2 / 3$ of their respective capacities. For this reason, in the power treatments, signaling cost changes should exacerbate rather than condense predicted differences in static Nash outcomes.

Differences in the likelihood that 'other' sellers will respond to a signal in a way that allows a signaler to profit from supra-competitive price postings in future periods represents a feature of the power treatments that is consistent with observed outcomes. In the $2 p$ treatment, the sole non-signaling 'other' seller must respond in order for a signal to 
be potentially profitable. In the $3 p$ treatment this 'follow rate' falls to $1 / 2$ as only one of the two non-signaling rivals must follow a signal for it to be effective. Reasoning similarly, the follow rate falls to $1 / 3$ in the $4 p$ treatment.

In contrast, in the strong no power design, all remaining rivals must raise transactions prices in the $2 n p$, 3np and $4 n p$ treatments, making the follow rates in each case 1, 2 and 3 respectively, reflecting the increased difficulty of getting both or all three other sellers to simultaneously respond to a signal with a price increase.

5.1. A Weak No Power Design. To test the notion that this 'follow rate' may explain tacit collusion we conducted an additional 12 markets in a pair of treatments that are a hybrid of the power and strong no power designs. The idea is simple: we increase excess capacity relative to the power treatment sufficiently to remove static market power (thus making signaling costs equal to those in the $n p$ treatments), but not so much as to affect the follow rates in the power treatments.

Figure 4 illustrates supply and demand arrays for three and four seller implementations of this 'weak no power' design. Sellers are endowed with nine units each period which can be offered at a constant $\$ 2$ per unit. For comparability with the strong no power designs, sellers may not post a price below $\$ 3$. When $n=2$, the automated buyer will purchase the entire capacity of one seller (making the $2 n p$ and $2 w p$ designs equivalent). When $n=3$ or 4 the buyer will purchase is $9 n-2$ units at prices of $\$ 6$ or less, making the follow rate fall from 1 to $1 / 2$ and then $1 / 3$, respectively. ${ }^{16}$

Using arguments identical to those used in the $n p$ design, one can readily verify that $\$ 3$ is a unique Nash equilibrium for each of the $w p$ treatments analyzed as a stage game. The novelty of this design is that to the extent the follow rate explains tacit collusion, we should observe (a) higher prices in the $3 w p$ and $4 w p$ markets than in their $3 n p$ and $4 n p$ counterparts (despite the fact that the competitive price is the unique static Nash equilibrium in each treatment) and (b) levels of tacit collusion in weak no power

\footnotetext{
${ }^{16}$ In constructing this design, seller endowments and demand equal nine units rather than the ten units shown in Figures 1 and 2. This change was inadvertent and in no way affects the analysis. Also, following Smith and Williams (1990) and Cason and Williams (1990) demand is set so that the seller posting the second highest price sells seven rather than all nine of his or her units. As Cason and Williams (1990) observe, this minor demand alteration allows a rank ordering of price choices in terms of sales quantities, a feature that is not terribly important here.
} 
treatment similar to those observed in comparable power treatments. This is a fourth conjecture.

Conjecture 4: The 'follow rate' predicts tacit collusion. In particular (a) tacit collusion in the 'weak no power' design will exceed that observed in the 'strong no power design', and (b) tacit collusion levels in the weak no power treatments will not differ from those observed in comparable power treatments.

The 3wp and 4wp markets were conducted in the fall semester of 2005 as a series of six additional sessions, using a total of 42 participants. In all critical respects, procedures for this second set of sessions paralleled those described for the initial sessions. However, unlike the earlier sequences, $w p$ sequences were not mixed either within or across sessions. That is, the six 3wp markets were conducted as a series of three nineparticipant sessions that included only 3wp markets. Similarly, the six $4 w p$ markets were conducted as a series of three twelve-participant sessions that included only $4 w p$ markets. Each $w p$ sequence was the second portion of a two-sequence session. ${ }^{17}$ Earnings in this second set of sessions ranged from \$15 to \$41.25 and averaged \$26.50.

5.2 Results- Weak No Power Sessions. As evidenced by the mean transactions price paths for the 3wp and $4 w p$ treatments shown in Figure 5, mean transactions prices very substantially exceed static Nash predictions in the $w p$ design, this despite the fact that the static Nash equilibrium is $\$ 3.00$, as in the strong no power treatments. Mean transactions prices for the first and second (post initial) 105-period segments of individual 3wp and $4 w p$ markets shown in Table 7 give some sense of the variability of outcomes within markets (we repeat results of the $2 n p$ markets here for purposes of comparison). Note in Table 7 the outcome variability parallels that observed in the power treatments.

Tables 8 and 9 allow a more formal evaluation of conjecture 4. Table 8 evaluates the null hypothesis that prices (and thus tacit collusion) is no higher in the three and four seller weak no power treatments than in their strong no power counterparts. As is clear from the entries, differences are uniformly large and significant. To assess the extent to which the weak no power design captures tacit collusion observed in the power

\footnotetext{
${ }^{17}$ The design in the first sequence of the wp sessions was a 'trend supply' design, parallel to the trend demand design studied in the near-continuous context by Davis and Korenok (2008) except that the supply curve rather than the demand curve was subjected to a series of first inflationary and then deflationary shocks. We have no reason to believe that this initial sequence affected participants in any way other than to allow them to become experienced with the near-continuous framework.
} 
treatments, Table 9 compares deviations from static Nash predictions across the power and weak no power treatments. Notice in Table 9 that the differences in mean deviations across treatments tend to be positive, indicating more tacit collusion in the weak no power treatments than in the power treatments. Although none of these differences are evenly weakly significant, these data do suggest that we observe at least as much tacit collusion in the weak no power treatments as in the power treatment. ${ }^{18}$ Results in Tables 8 and 9 combine to form a final finding.

Finding 4: The 'follow rate' is consistent with important dimensions of observed tacit collusion. Prices in 'weak no power' treatments significantly exceed prices in their counterpart 'strong no power' treatments. Further, deviations from static Nash predictions in weak no power treatments do not significantly differ from those observed in comparable power treatments.

\section{Discussion}

This paper reports an experiment conducted in an extensively repeated 'nearcontinuous' framework to examine factors that affect tacit collusion in laboratory postedoffer markets. We find that neither concentration nor extensive repetition exert the expected effects of importantly increasing tacit collusion. Results of markets in a strong no power design show that tacit collusion is not an inherent feature of posted offer markets when very extensively repeated. Further, although we observed instances of tacit collusion in the strong no power duopolies, this treatment is not importantly impacted by tacit collusion. Results of 'power' design markets indicate that unilateral market power raises prices relative to the strong no power design, as predicted. However, the central moments of the static mixing distribution do not organize observed prices within the power design treatments because tacit collusion tends to increase as the number of sellers is expanded beyond two. Observing that no obvious 'language of coordination' evolves in any of our markets, we suggest that relatively unstructured signaling and response activity may explain the tacit collusion in our markets, and conjecture that a 'follow rate' which reflects the number (or, if only a subset is needed the percentage) of 'other' sellers in a market that must follow a signal in order for the signaler to profit from his action in a

\footnotetext{
${ }^{18}$ Notice that unlike results reported in the other tables, two-tailed tests are appropriate here, because the null hypothesis is that deviations prices in the power and no power treatments are the same.
} 
future period explains tacit collusion. In a follow up experiment we find some support for this conjecture. ${ }^{19}$

These results are important, both from the perspective of behavioral market research and for policy purposes. For laboratory market research, our results offer two insights. First is the procedural insight that extensive repetition may, in many instances, not importantly affect tacit collusion. Although sellers clearly need a limited number of initial adjustment periods, behavior did not importantly change thereafter. Thus, our results suggest that outcomes in standard 35-40 period laboratory markets may in many instances elicit results that do not differ substantially from what would be observed in markets of substantially longer duration. Second, and perhaps more fundamentally, results here indicate that while tacit collusion is not a pervasive phenomenon in posted offer markets, the combined design properties of (a) a competitive equilibrium that is a unique Nash equilibrium for the market stage game, and (b) a structure with more than two sellers, are generally not sufficient to generate a behaviorally competitive outcome.

The potential policy implications of our results follow from this latter observation. Our point is not that a duopoly structure is necessarily competitive. To the contrary, the only instances of significant tacit collusion we observed in our strong no power design occurred in the $2 n p$ treatment. Rather, our point is that less concentrated structures exist that are even more susceptible to tacit collusion than duopolies.

To some degree, the definition of antitrust markets in the US Department of Justice/ Federal Trade Commission Horizontal Merger Guidelines may anticipate the competitive problems we observe here. Under the Guidelines, an antitrust market for a non price-discriminating industry is defined as the smallest set of sellers, who, acting in a hypothetical conspiracy could effect "at least a small but significant and nontransitory price increase" (Sec. 1.11). Here, for example, in the weak no power markets, just two sellers must raise prices to the $\$ 6$ upper limit to increase profits, suggesting that both the $3 w p$ and $4 w p$ structures may be regarded as duopolies for antitrust purposes. Similarly,

\footnotetext{
${ }^{19}$ The follow rate is largely determined by excess capacity. In an earlier version of this paper, we also observe that in our design excess capacity and the 'Friedman coefficient' or the minimum discount rate necessary to support tacit collusion as a grim 'trigger strategy' equilibrium (Friedman, 1971) are very highly correlated. We are, however, skeptical that it is changes in discount rate that drive observed tacit collusion. As we noted in Table 6, there is very little to suggest that sellers engaged in the sort of coordinated activity consistent with such an equilibrium, even in markets characterized by very substantial levels of tacit collusion.
} 
via this reasoning each of the power treatments may be regarded as monopolies for antitrust purposes.

However, the Guidelines' market definition test is perhaps importantly deficient in that it appears to focus on the profitability of small price increases. ${ }^{20}$ In the weak no power treatments only very large price increases above a competitive level are profitable. Thus, our 3wp and 4wp markets would likely not be identified as duopolies, and our power markets would not be identified as monopolies. ${ }^{21}$ That tacit collusion appears to be more of a problem in our three and four seller power and weak no power treatments than in comparable duopolies enhances the potential importance of this deficiency.

One possible approach for practically addressing this potential shortcoming in antitrust market definition would involve increased attention to excess capacity. Both signaling costs (measured as static market power) and follow rates are directly related to excess capacity. Starting from a context that elicits competitive outcomes, initial excess capacity reductions reduce the follow rate, increasing the likelihood of tacit collusion. Still further excess capacity reductions reduce signaling costs as they create unilateral market power. Results of our laboratory markets suggest that small amounts of excess capacity or perhaps efforts by sellers to acquire and remove excess capacity may be important indicators of likely tacit collusion, even in relatively unconcentrated markets, and even in the absence of any obvious mechanisms for coordination or enforcement. ${ }^{22}$ In any case, our results suggest that further attention to the effects of excess capacity on tacit collusion is warranted.

\footnotetext{
${ }^{20}$ Although the Guidelines do not exclude the possibility of larger price increases, the focus is clearly on small increases. For example, the Guidelines take care to objectively identify a 'small but significant and not transitory price increase' as a 5\% increase for the foreseeable future, but offer not discussion of when the consideration of larger price increases might be appropriate.

${ }^{21}$ The unilateral effects described in section 2.2 of the Guidelines would potentially identify as problematic a change in the static Nash equilibrium induced by the introduction of market power. However, the current Guidelines would not anticipate the tacit collusion in the form of price above the Nash equilibrium we observe in our $3 p$ and $4 p$ markets

${ }^{22}$ For example, the FTC's complaint against Arch Coal et al. (2004) would seem to fit this prescription. The merger involved a consolidation from 4 sellers to 3 in the production of a grade of high BTU Coal in the Western U.S. (or 5 sellers to 5, but with an HHI increase, in the production of combined 'higher grade' BTU coals.) Sellers were capacity constrained, and Arch Coal appeared to be purchasing excess capacity and removing it from production. District Judge John D. Bates dismissed the FTC's case, because the Commission failed to provide satisfactory evidence of coordinated post-merger activity. See FTC vs. Arch Coal et al. 04-0534, August 16, 2004.
} 


\section{References}

Alger, D., 1987. Laboratory Tests of Equilibrium Predictions with Disequilibrium Data. Review of Economic Studies 45, 105-145.

Cason, T., Williams, A. W., 1990. Competitive Equilibrium Convergence in a PostedOffer Markets with Extreme Earnings Inequities. Journal of Economic Behavior and Organization 14, 331-352.

Cripps, M. W., Ireland, N.J., 1988. Equilibrium Capacities in a Market of Fixed Size. Manuscript, University of Warwick.

Davis, D. D., Holt, C. A., 1994. Market Power and Mergers in Laboratory Markets with Posted Prices. RAND Journal of Economics 25: 467-487.

Davis, D. D., Holt C. A., Villamil, A. P., 2002. Supra-Competitive Prices and Market Power in Posted-Offer Markets. In Isaac. R.M., Holt C. A. (Eds.). Experiments Investigating Market Power, Research in Experimental Economics vol. 9, Oxford: JAI Press, 121-138.

Davis, D. D., Korenok, O., 2008. Posted-Offer Markets in Near Continuous Time: An Experimental Investigation. Economic Inquiry (in press).

Davis, D. D., Korenok, O., Reilly, R. J., 2008a. Re-matching, Information and Sequencing Effects in Posted Offer Markets. Experimental Economics (in press).

Davis, D. D., Korenok, O., Reilly, R.J., 2008b. Cooperation without Coordination: Signaling, Types and Tacit Collusion in Laboratory Oligopolies. Manuscript, Virginia Commonwealth University.

Deck, C. A., Wilson, B. J., 2008. Experimental Gasoline Markets. Journal of Economic Behavior and Organization, 67, 134-149.

Deck, C. A., Wilson, B. J., 2002. The Effectiveness of Low Price Matching in Mitigating the Competitive Pressure in Low Friction Electronic Markets. Electronic Commerce Research, 2, 385-398.

Dufwenberg, M., Gneezy U., 2000. Price Competition and Market Concentration: An Experimental Study. International Journal of Industrial Organization 18, 7-22.

Fouraker L. E., Siegel, S., 1963. Bargaining Behavior. New York: McGraw Hill.

Freidman, J. W., 1971. A Noncooperative Equilibrium for Supergames. Review of Economic Studies 38, 1-12.

Huck, S., Normann, H. T. Oechssler, J., 2004. Two Are Few and Four Are Many: Number Effects in Experimental Oligopolies. Journal of Economic Behavior and Organization 53, 435-446.

Isaac, R.M., Ramey, V., Williams, A.W., 1984. Market Organization and Conspiracies in Restraint of Trade. Journal of Economic Behavior and Organization, 5, 191-222.

Isaac, R. M., Reynolds, S. M., 2002. Two or Four Firms: Does it Matter? In Holt C. A., Isaac, R. M. (Eds.) Research in Experimental Economics, Vol. 9: Experiments Investigating Market Power. Elsevier Science Ltd: Oxford, UK, 95-120.

Ketcham, J., Smith, V. L., Williams, A.W., 1984. A Comparison of Posted-Offer and Double-Auction Pricing Institutions Review of Economic Studies 51, 595-614.

Orzen, H., 2008. Counterintutive Number Effects in Experimental Oligopolies. Experimental Economics 11, 390-401.

Plott, C. R., 1989. An Updated Review of Industrial Organization Applications of Experimental Methods,” In Schamlensee, R., Willig, R. (Eds.). Handbook of 
Industrial Organization, Vol. 2. Amsteram: Elsevier Science Publishers, 11111176.

Potters, J., Suetens, S., 2008. Strategic Interaction, Externalities and Cooperation: Experimental Evidence. Review of Economic Studies (in press)

Smith, V. L., 2003. Constructivist and Ecological Rationality in Economics. American Economic Review 93, 465-508.

Smith, V. L., 1982. Microeconomic Systems as an Experimental Science. American Economic Review, 72, 923-955.

Smith, V. L.,Williams, A. W., 1990. The Boundaries of Competitive Price Theory: Convergence, Expectations and Transactions Costs. In Green L., Kagel, J. (Eds). Advances in Behavioral Economics, Vol. 2, New York: Ablex Publishing. 3-35.

U.S. Department of Justice and Federal Trade Commission Horizontal Merger Guidelines, 1997. 


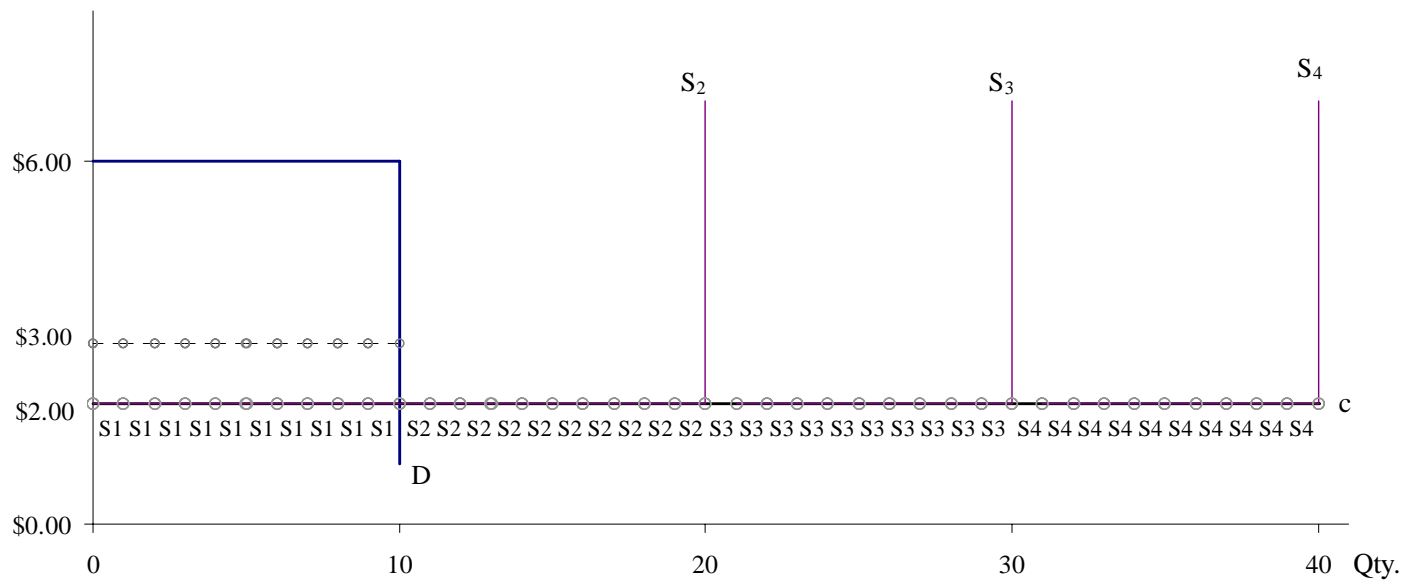

Figure 1. The Strong No-Power ('np') Design

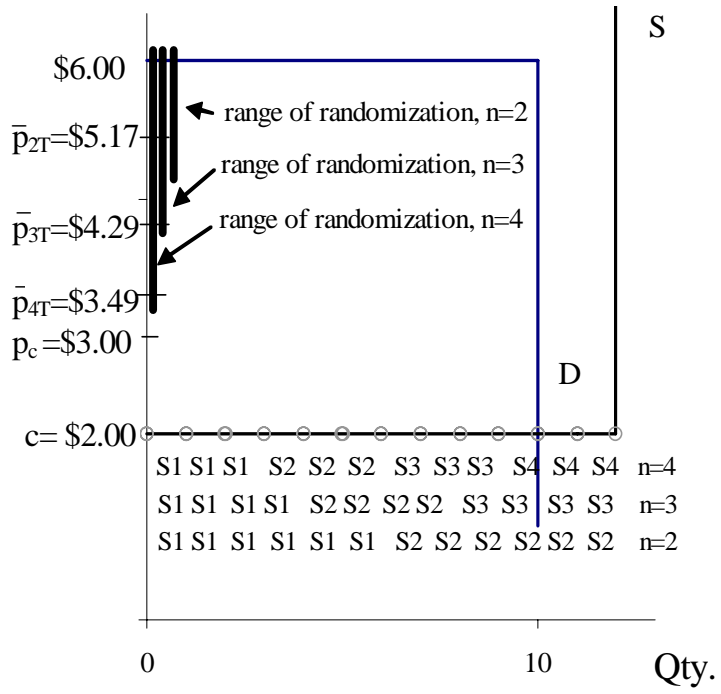

Figure 2. The Power (' $p$ ') Design 

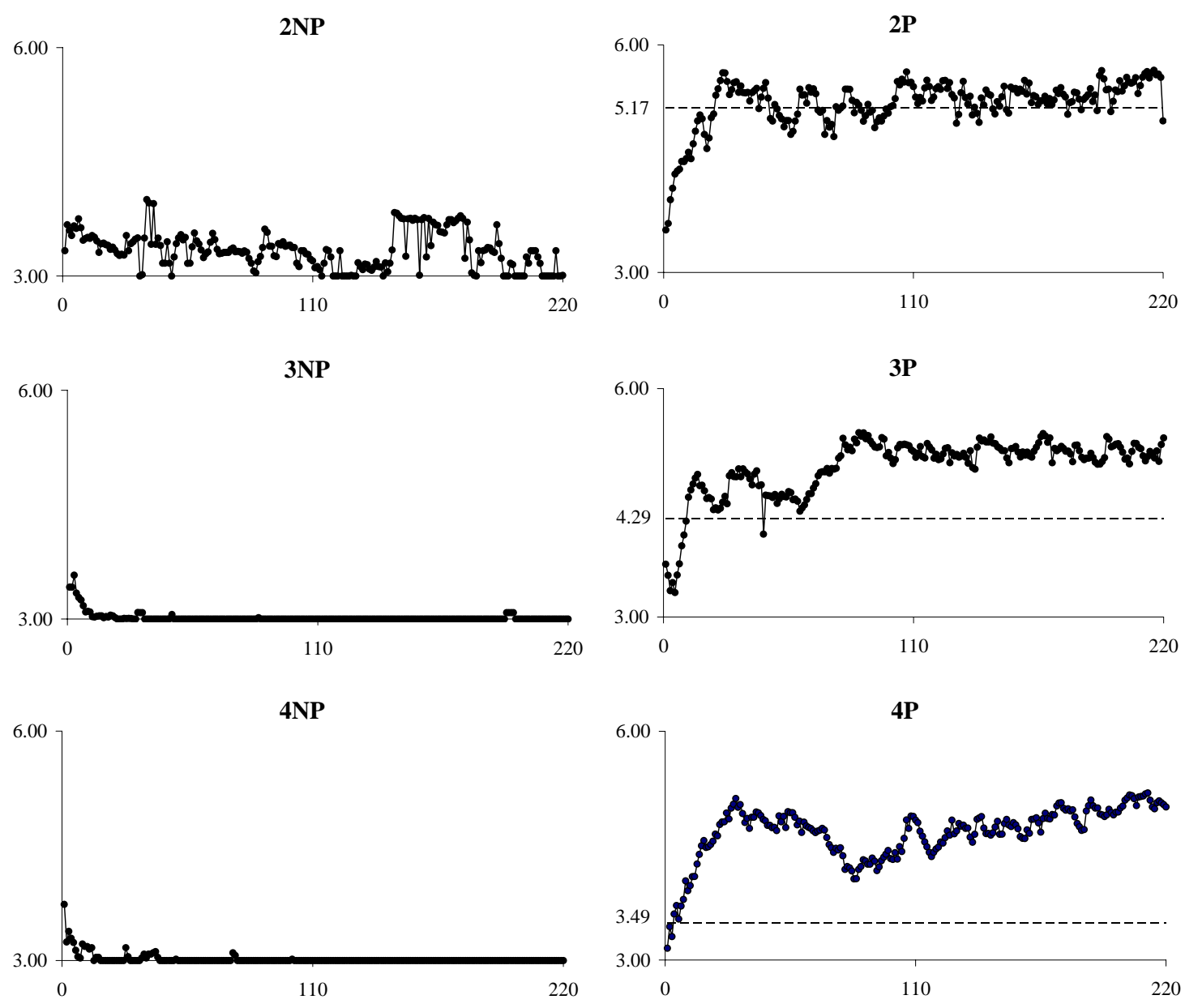

Figure 3. Mean Transactions Prices for the No-Power and Power Treatments. 


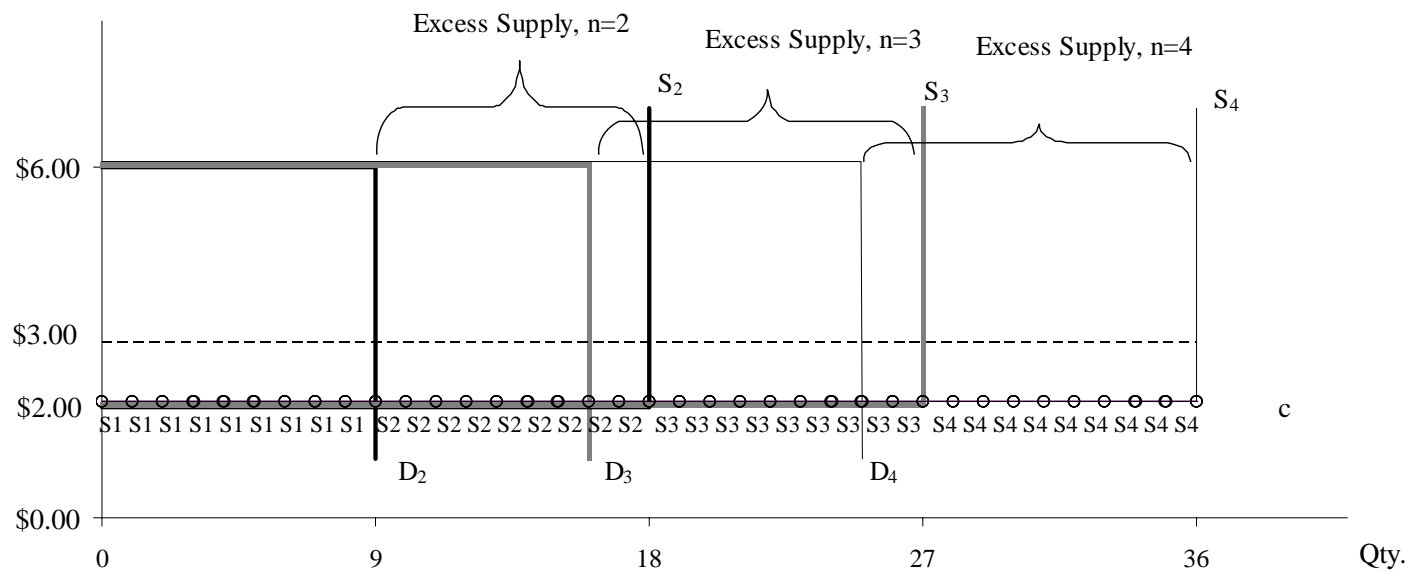

Figure 4. The Weak No-Power ('wp') Design
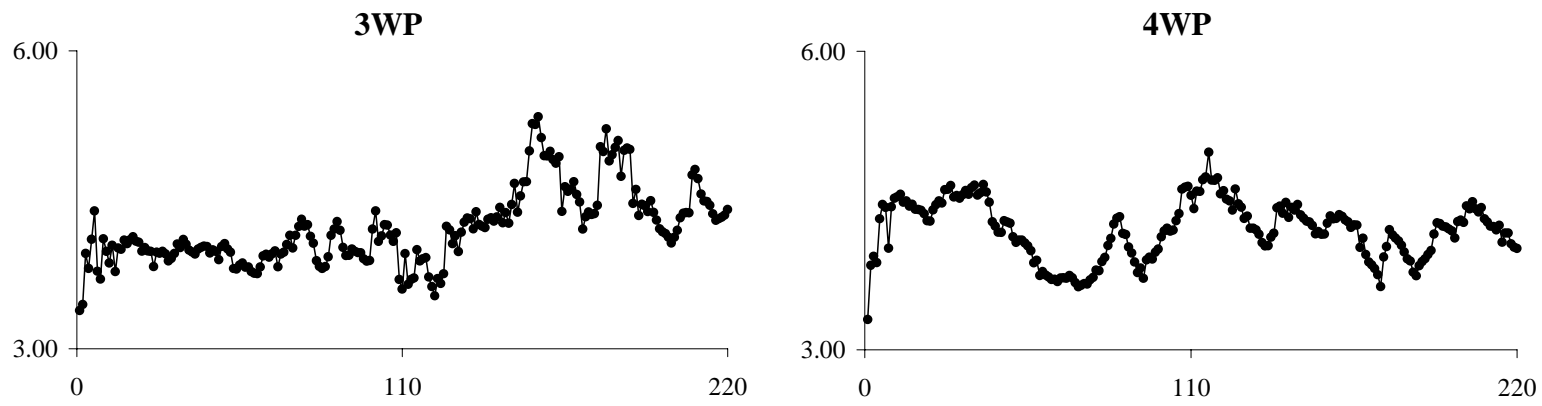

Figure 5. Mean Transactions prices for the $3 w p$ and $4 w p$ treatments. 
Table 1. Mean Static Price Predictions, Strong No Power and Power Designs $(\mathbb{\$})$

(1) Strong No Power Design
(2) Power Design

\begin{tabular}{cccc}
\hline Treatment & $\bar{p}_{n p T}$ & Treatment & $\bar{p}_{p T}$ \\
\hline $4 n p$ & 300 & $4 p$ & 349 \\
$3 n p$ & 300 & $3 p$ & 429 \\
$2 n p$ & 300 & $2 p$ & 517 \\
\hline
\end{tabular}

Table 2. Mean Transaction Prices by Treatment ( $\mathbb{C}$ ) Strong No Power Treatments

\begin{tabular}{|c|c|c|c|c|c|c|}
\hline \multicolumn{4}{|c|}{ Periods 11-115 } & \multicolumn{3}{|c|}{ Periods 116-220 } \\
\hline Market & $2 n p$ & 3np & $4 n p$ & $2 n p$ & $3 n p$ & $4 n p$ \\
\hline$i$ & 383 & 301 & 301 & 300 & 300 & 300 \\
\hline ii & 327 & 302 & 300 & 400 & 300 & 300 \\
\hline iii & 312 & 301 & 300 & 383 & 300 & 300 \\
\hline iv & 301 & 301 & 303 & 300 & 302 & 300 \\
\hline$v$ & 306 & 300 & 300 & 301 & 300 & 300 \\
\hline$v i$ & 388 & 300 & 305 & 306 & 300 & 300 \\
\hline $\bar{p}_{T}$ & 336 & 301 & 302 & 332 & 300 & 300 \\
\hline $\bar{p}_{N E T}$ & 300 & 300 & 300 & 300 & 300 & 300 \\
\hline \multicolumn{7}{|c|}{ Power Treatments } \\
\hline Market & $2 p$ & $3 p$ & $4 p$ & $2 p$ & $3 p$ & $4 p$ \\
\hline$i$ & 508 & 563 & 490 & 547 & 556 & 474 \\
\hline$i i$ & 538 & 546 & 413 & 533 & 576 & 484 \\
\hline$i i i$ & 564 & 377 & 553 & 557 & 479 & 576 \\
\hline iv & 498 & 496 & 486 & 562 & 464 & 357 \\
\hline$v$ & 452 & 463 & 326 & 444 & 462 & 461 \\
\hline$v i$ & 545 & 484 & 493 & 571 & 569 & 557 \\
\hline $\bar{p}_{T}$ & 518 & 488 & 460 & 536 & 518 & 485 \\
\hline $\bar{p}_{N E T}$ & 517 & 429 & 349 & 517 & 429 & 349 \\
\hline
\end{tabular}


Table 3. Mean Differences, Strong No Power Design (\$)

\begin{tabular}{|c|c|c|c|}
\hline \multicolumn{4}{|c|}{ Concentration - Relative Effects } \\
\hline & (1) & (2) & (3) \\
\hline $\mathrm{H}_{\mathrm{o}}:$ & $\bar{p}_{2 n p T}-\bar{p}_{3 n p T} \leq 0$ & $\bar{p}_{2 n p T}-\bar{p}_{4 n p T} \leq 0$ & $\bar{p}_{3 n p T}-\bar{p}_{4 n p T} \leq 0$ \\
\hline $1^{\mathrm{st}}$ & $36^{* *}$ & $35^{* *}$ & -1 \\
\hline $2^{\text {nd }}$ & 31 & $32^{* *}$ & 0 \\
\hline \multicolumn{4}{|c|}{ Concentration - Absolute Effects } \\
\hline $\mathrm{H}_{\mathrm{o}}{ }^{\mathrm{i}}$ & $\bar{p}_{2 n p T}-\bar{p}_{N E} \leq 0.30$ & $\bar{p}_{2 n p T}-\bar{p}_{N E} \leq 0.30$ & $\bar{p}_{4 n p T}-\bar{p}_{N E} \leq 0.30$ \\
\hline $1^{\mathrm{st}}$ & 36 & 1 & 2 \\
\hline $2^{\text {nd }}$ & 32 & 0 & 0 \\
\hline \multicolumn{4}{|c|}{ Repetition Effects } \\
\hline $\mathrm{H}_{0}:$ & $\bar{p}_{2 n p 2 T}-\bar{p}_{2 n p 1 T} \leq 0$ & $\bar{p}_{3 n p 2 T}-\bar{p}_{3 n p 1 T} \leq 0$ & $\bar{p}_{4 n p 2 T}-\bar{p}_{4 n p 1 T} \leq 0$ \\
\hline $2^{\text {nd }}$ vs. $1^{\text {st }}$ & $\begin{array}{l}\mathrm{t} \\
\mathrm{t}\end{array}$ & -1 & -2 \\
\hline
\end{tabular}

Table 4. Mean Differences Across Power and Strong No Power Designs (\$)

\begin{tabular}{|c|c|c|c|}
\hline \multicolumn{4}{|c|}{ Mean Price Differences } \\
\hline $\mathrm{H}_{\mathrm{o}}:$ & (1) & (2) & (3) \\
\hline & $\bar{p}_{2 p T}-\bar{p}_{2 n p T} \leq 0$ & $\bar{p}_{3 T}-\bar{p}_{3 n p T} \leq 0$ & $\bar{p}_{4 p T}-\bar{p}_{4 n p T} \leq 0$ \\
\hline $1^{\text {st }}$ & $181^{* * *}$ & $188^{* * *}$ & $159^{* * *}$ \\
\hline $2^{\text {nd }}$ & $204^{* * *}$ & $217^{* * *}$ & $185^{* * *}$ \\
\hline \multicolumn{4}{|c|}{ Repetition and Mean Prices in Power Treatments } \\
\hline $\mathrm{H}_{\mathrm{o}}:$ & $\bar{p}_{2 p 2 T}-\bar{p}_{2 p 1 T} \leq 0$ & $\bar{p}_{3 p 2 T}-\bar{p}_{3 p 1 T} \leq 0$ & $\bar{p}_{4 p 2 T}-\bar{p}_{4 p 1 T} \leq 0$ \\
\hline $2^{\text {nd }}$ VS. $1^{\text {st }}$ & 18 & 29 & 25 \\
\hline
\end{tabular}


Table 5. Mean Differences, Power Design ( $\$$ )

\begin{tabular}{|c|c|c|c|}
\hline \multicolumn{4}{|c|}{ Concentration - Relative Differences } \\
\hline & (1) & (2) & (3) \\
\hline $\mathrm{H}_{\mathrm{o}}:$ & $\bar{p}_{2 p T}-\bar{p}_{3 p T} \leq 0$ & $\bar{p}_{2 p T}-\bar{p}_{4 p T} \leq 0$ & $\bar{p}_{3 p T}-\bar{p}_{4 p T} \leq 0$ \\
\hline $1^{\text {st }}$ & 29 & $57^{* *}$ & 28 \\
\hline $2^{\text {nd }}$ & 1 & 51 & 33 \\
\hline \multicolumn{4}{|c|}{ Concentration - Absolute Differences } \\
\hline $\mathrm{H}_{\mathrm{o}}:$ & $\left(\bar{p}_{2 p T}-\bar{p}_{2 N E T}\right) \leq 0.30$ & $\left(\bar{p}_{3 p T}-\bar{p}_{3 N E T}\right) \leq 0.30$ & $\left(\bar{p}_{4 p T}-\bar{p}_{4 N E T}\right) \leq 0.30$ \\
\hline $1^{\text {st }}$ & 1 & $59^{\dagger}$ & $111^{\dagger \dagger}$ \\
\hline $2^{\text {nd }}$ & 19 & $89^{+\dagger}$ & $136^{\dagger \dagger}$ \\
\hline
\end{tabular}

Table 6. Some Indicators of Cooperative Behavior (\%) Identical Supra-Competitive Prices. Repeated Quantity Rotation

(1)

(2)

(3)

(5)

(6)

Periods:

11-115

116-220

11-115

116-220

Strong No Power ( $n p)$ Design

\begin{tabular}{ccccc}
\hline $4 n p$ & 0 & 0 & 0 & 0 \\
$3 n p$ & 0 & 0 & 0 & 0 \\
$2 n p$ & 5.2 & 5.6 & 3 & 1 \\
\multicolumn{5}{c}{ Power $(p)$ Design } \\
\hline $4 p$ & 1.3 & 0 & 0 & 0 \\
$3 p$ & 2.1 & 1.4 & 0 & 0 \\
$2 p$ & 5.9 & 4.0 & 2.7 & 1.2 \\
\hline
\end{tabular}


Table 7. Mean Transaction Prices: Weak No Power Treatment (\$)

\begin{tabular}{rcccccc}
\multicolumn{8}{c}{ Strong No Power Treatments } \\
\hline \multirow{8}{*}{ Market } & \multicolumn{7}{c}{ Periods 11-115 } & \multicolumn{7}{c}{ Periods 116-220 } \\
\cline { 2 - 7 }$i$ & 383 & 366 & 458 & 300 & 453 & 509 \\
$i i$ & 327 & 500 & 394 & 400 & 565 & 392 \\
$i i i$ & 312 & 451 & 499 & 383 & 393 & 425 \\
$i v$ & 301 & 308 & 393 & 300 & 365 & 315 \\
$v$ & 306 & 399 & 418 & 301 & 489 & 419 \\
$v i$ & 388 & 367 & 348 & 306 & 397 & 476 \\
$\bar{p}_{T}$ & 336 & 399 & 418 & & & \\
$\bar{p}_{N E T}$ & 300 & 300 & 300 & 332 & 444 & 423 \\
\hline
\end{tabular}

Table 8. Mean Transaction Price Comparisons: Weak No Power vs. Strong No Power Designs (\$)

\begin{tabular}{lcc}
\hline \multicolumn{3}{c}{ Mean Price Differences } \\
\hline $\mathrm{H}_{\mathrm{o}}:$ & $(1)$ & $(2)$ \\
& $\bar{p}_{3 w p T}-\bar{p}_{3 n p T} \leq 0$ & $\bar{p}_{4 w p T}-\bar{p}_{4 n p T} \leq 0$ \\
$1^{\text {st }}$ & $98^{* * *}$ & $117^{* * *}$ \\
$2^{\text {nd }}$ & $143^{* * *}$ & $123^{* * *}$ \\
\hline
\end{tabular}

Notes: $1^{\text {st. }}$ periods $11-115,2^{\text {nd }}$ : periods $116-220 .{ }^{* * *} p<.01$ permutation tests (one tailed)

Table 9. Differences in Mean Deviations Static Nash Predictions: Power vs. Weak No Power Designs (\$)

\begin{tabular}{lccc}
\hline $\mathrm{H}_{\mathrm{o}}:$ & $(1)$ & $(2)$ & $(3)$ \\
& $\bar{p}_{2 w p T d e v}-\bar{p}_{2 p T d e v}=0$ & $\bar{p}_{3 w p T d e v}-\bar{p}_{3 p T d e v}=0$ & $\bar{p}_{4 w p T d e v}-\bar{p}_{4 p T d e v}=0$ \\
$1^{\text {st }}$ & 36 & 39 & 7 \\
$2^{\text {nd }}$ & 13 & 55 & -13 \\
\hline
\end{tabular}

Notes: Each test compares the deviation of mean transaction prices from the static Nash equilibrium prediction for the treatment. $1^{\text {st: }}$ : periods $11-115,2^{\text {nd }}$ : periods $116-220 . * p<.10$ permutation test (two tailed) 